\title{
Protease activity involvement in the passage of mammalian sperm through the zona pellucida
}

\author{
Ricardo D. Moreno*, Andrea Laserre, A. and Claudio Barros \\ Departamento de Fisiología, Pontificia Universidad Católica de Chile.
}

\begin{abstract}
The interaction between acrosome-reacted sperm and zona pellucida proteins is not yet fully understood. Serine protease acrosin and its zymogen proacrosin have been proposed to fulfill this function due to their capacity to bind zona pellucida glycoproteins. However, the molecular mechanism underlying this interaction has been merely speculative. Here we show that fucoidan (a sulfated polysaccharide) and solubilized zona pellucida glycoproteins, but not soybean trypsin inhibitor, are able to detach bound spermatozoa, which suggests that live sperm binds to the zona pellucida in a non-enzymatical way. Interestingly, mild proteolytic digestion with acrosin or trypsin does not modify the structure of the zona pellucida, but rather results in fewer spermatozoa binding to the zona. These results agree with a model where the active site of acrosin digests the zona pellucida and binds through the polysulfate-binding domain through a three-dimensional zona structure rather than a single ligand.
\end{abstract}

Key words: Fertilization, acrosin, acrosome, zona pellucida, sperm.

\section{INTRODUCTION}

Three proteins are recognized as the structural components of mouse zona pellucida, namely ZP1, ZP2 and ZP3 (Wassarman, 2008). In order to penetrate the zona pellucida, as one hypothesis states, acrosome-intact sperm recognizes and binds with a single O-linked oligosaccharides chain, which is probably ZP3 (Florman and Wassarman, 1985; Wassarman et al., 2001). On the other hand, a ZP2 cleavage model has recently been proposed that argues that rather than sperm binding to a single ligand, sperm binding is supported by a three-dimensional zona structure (Gahlay et al., 2010; Rankin et al., 2003). This model is predicated on the cleavage status of $\mathrm{ZP}$, rendering the zona pellucida either permissive (uncleaved $\mathrm{ZP2}$ ) or non-permissive (cleaved ZP2) to account for sperm binding to the zona pellucida surrounding eggs, but not to those surrounding two-cell embryos (Gahlay et al., 2010; Rankin et al., 2003). ZP2 has also been proposed as a binding partner of acrosome-reacted sperm (Bleil et al., 1988; Howes and Jones, 2002). Experimental evidence suggests that ZP2 binds and that it is the substrate of acrosin, a serine-protease located in the acrosome (Howes et al., 2001; Howes and Jones, 2002). Acrosome-intact spermatozoa bear a non-active (pro) acrosin, which is activated upon acrosome reaction (Barros et al., 1996; Codelia et al., 2005; Cortes et al., 2006; Moreno and Alvarado, 2006). Different studies have shown that acrosin can digest zona pellucida glycoproteins and it is believed that its enzyme activity is involved in the cleavage of ZP2 during fertilization (Florman and Wassarman, 1985; Gahlay et al., 2010). However, there is no experimental evidence that zonaintact eggs treated with acrosin, or another serine-protease, are impervious to fertilization. This kind of experimental evidence would help to support or refute the ZP2 cleavage model of zona pellucid penetration.
Proacrosin and acrosin are capable of binding polysulphated compounds, such as fucoidan, chondroitin sulfates A, B, C and dextran sulphate, as well as the glycan chains of solubilized zona pellucida glycoproteins (ZPG's) (Crosby et al., 1998; Jones, 1989; Jones, 1991). This polysulphated-binding domain (PSBD) must be different from the active site since neither specific inhibitors or mutations in the active-site amino acids affect acrosin interaction with those compounds (Lo Leggio et al., 1994; Moreno and Barros, 2000; Moreno et al., 1999; Moreno et al., 1998). Many biochemical and site-mutagenesis studies of different species have shown that the PSBD encompasses basic aminoacids (Crosby et al., 1998; Jansen et al., 1998; Moreno and Barros, 2000; Richardson and O'Rand, 1996). In addition, an 18-amino acid peptide, containing those basic residues, is able to inhibit the activation of proacrosin induced by either fucoidan or solubilized zona pellucida glycoproteins (ZPG's) (Crosby et al., 1998; Jansen et al., 1998; Moreno and Barros, 2000; Richardson and O'Rand, 1996). The role of the second PSBD in sperm-zona pellucida binding during fertilization remains to be determined.

The aims of this work were to determine whether proteolytic modification of the zona pellucida by acrosin can modify the binding and/or penetration of spermatozoa, and to evaluate in more detail the contribution of the PSBD in sperm passage through the zona pellucida.

\section{MATERIALS AND METHODS}

Reagents

Unless otherwise stated, all chemicals and reagents were purchased from Sigma (St Louis, MO) or Merck (Darmstadt, Germany). 
Hamster gamete collection and in vitro fertilization

Hamster sperm capacitation: Hamster spermatozoa were obtained from the caudal epidydimidis of 3-4-month-old animals and maintained in TALP-10K medium supplemented with $10 \mathrm{mg} / \mathrm{ml}$ bovine serum albumin (Jedlicki et al., 1988). To achieve capacitation, the spermatozoa were incubated in drops of $100 \mathrm{ml}$ under mineral oil for $3 \mathrm{~h}$ at a concentration of $1.5 \mathrm{x}$ $10^{6}$ per $\mathrm{ml}$, in a $5 \% \mathrm{CO}_{2}$ atmosphere.

Hamster oocyte collection: Adult female hamsters were induced to superovulate with an injection of 30 IU of PMSG (Pregnant Mare's Serum gonadotropin), on a day of prooestrous discharge (Jedlicki et al., 1988). Fifty to 60 hours later, they were injected with 30 IUof hCG (human chorionic godanotrophin) and sacrificed 14-15 hours later. Hamster oocytes in cumuli were removed and placed in TALP$10 \mathrm{~K}$, supplemented with $10 \mathrm{mg} / \mathrm{ml} \mathrm{BSA}$, incubated for 3-5 min with $0.1 \%$ hyaluronidase prepared in TALP-10K, and washed thoroughly in three changes of fresh medium. Mouse and hamster zona-intact eggs were then used for in vitro fertilization.

Hamster In vitro Fertilization: Hamster in vitro fertilization was achieved by adding the zona-intact oocytes to the capacitated sperm drops, and incubated for 3 hours. After gamete co-incubation, the number of sperm bound to and having penetrated the zona pellucida, as well as the rate of penetration and fertilization, was evaluated by phase contrast microscopy (Jedlicki et al., 1988; Moreno et al., 2001).

\section{Proacrosin extraction and activation}

Boar proacrosin was obtained by extraction as described previously (Moreno et al., 1999; Moreno et al., 1998). Briefly, boar semen ejaculate was adjusted with $1 \mathrm{M}$ benzamidine to a final concentration of $50 \mathrm{mM}$ and filtered through Miracloth. Twenty-ml aliquots were carefully placed in $25 \mathrm{ml}$ of $1 \mathrm{M}$ sucrose, $50 \mathrm{mM}$ benzamidine, $0.02 \%$ sodium azide, and were centrifuged for $30 \mathrm{~min}$ at $500 \mathrm{rpm}$ in an IEC HNS clinical centrifuge at room temperature. Boar acrosin was extracted in an acid solution containing $1 \mathrm{mM} \mathrm{HCl}, 10 \%$ glycerol, $0.02 \%$ sodium azide and $50 \mathrm{mM}$ benzamidine at $\mathrm{pH} 3.0$, and left at $4^{\circ} \infty \mathrm{C}$ overnight. This suspension was then centrifuged at $27,000 \mathrm{~g}$ for $30 \mathrm{~min}$ in a Sorvall model RC2-B centrifuge and the supernatant stored at $-20^{\circ} \infty \mathrm{C}$. Prior to the experiment, a 200 $\mathrm{ml}$ aliquot of frozen boar proacrosin was dialyzed overnight against $2 \mathrm{~L}$ of $1 \mathrm{mM} \mathrm{HCl}$ at $\mathrm{pH} 3.0$.

\section{Acrosin activity assay}

Acrosin activity was measured spectrophotometrically at $25^{\circ} \infty \mathrm{C}$ by following the hydrolysis of N-benzoyl-L-arginineethyl-ester (BAEE), after the addition of either 50 or $100 \mathrm{ml}$ of the enzyme solution (Moreno et al., 1999; Moreno et al., 1998). The assays were performed in $3 \mathrm{ml}$ volumes, using a substrate mixture of $50 \mathrm{mM}$ Tris- $\mathrm{HCl}, 50 \mathrm{mM} \mathrm{CaCl}_{2}$ and 500 $\mathrm{mM}$ BAEE at $\mathrm{pH}$ 8.0. A molar absorption coefficient of 1150 $\mathrm{M}^{-1} \mathrm{~cm}^{-1}$ was used to convert changes in optical density to mmoles of BAEE hydrolyzed. One international unit (IU) was defined as the amount of acrosin hydrolyzing 1 mmol BAEE/ $\min$ at $25^{\circ} \infty \mathrm{C}$.
Zona pellucida isolation and solubilization

Solubilized boass zona pellucida glycoproteins (ZPG's) were obtained from ovaries were isolated from cooled $\left(4^{\circ} \mathrm{C}\right)$ slaughterhouse according to a previous work (Moreno et al., 1999; Moreno et al., 1998).

Scanning electron microscopy

Fertilized hamster oocytes were processed for scanning electron microscopy as described before (Jedlicki et al., 1988). Briefly, the inseminated eggs were fixed, dehydrated in a series of increasing concentrations of acetone, critical-point dried in $\mathrm{CO}_{2}$ (Sorvall, Newton, CT; model 49300), sputtered and coated with palladium-gold (SEM Coating Unit 9000; Pelco, Redding, CA), and analyzed using a scanning electron microscope (JeolJSM-25 SII; Peabody, MA)

\section{Statistical analysis}

Variance analysis (ANOVA) was used to compare means after arc-sine transformation of PARS, as described before (Sokal, 1995). When the ANOVA test showed statistical differences, the Student-Newman-Keuls (SNK) test was used to compare groups; the t-student test was used to compare frequency. Significance is defined as $\mathrm{p}<0.05$ or $\mathrm{p}<0.01$.

Biological Assays

1. Effect of fucoidan, ZPG's and SBTI on the number of sperm bound to the surface of zona-intact hamster oocytes

Zona-intact hamster oocytes (pre-incubated with or without acrosin) were incubated for 3-4 h with capacitated sperms as described previously. The drops were exposed to fucoidan $(10 \mathrm{mg} / \mathrm{ml})$, solubilized ZPG's $(5 \mathrm{mg} / \mathrm{ml})$ or soybean trypsin inhibitor (SBTI) $(10-40 \mathrm{mg} / \mathrm{ml})$. After these treatments, the oocytes were thoroughly washed in PBS-BSA and then examined by phase contrast microscopy or fixed for scanning electron microscopy. At least 100 oocytes were counted in each group.

2. Pre-incubation of zona-intact hamster oocytes with boar acrosin or trypsin

Zona-intact hamster oocytes were pre-incubated with 1.5 or $3 \mathrm{U}$ of acrosin extract (155 $\mathrm{U} / \mathrm{mg}$ protein), and $1.5 \mathrm{U}$ of trypsin $\left(15.5 \times 10^{3} \mathrm{U} / \mathrm{mg}\right.$ protein) for 5 and $10 \mathrm{~min}$ in TALP10K medium without BSA. After treatment, the oocytes were washed several times in TALP-10K medium containing 10mg/ $\mathrm{ml} \mathrm{BSA}$ and then added to capacitated sperm drops. At the end of incubation the eggs were examined by phase contrast microscopy to determine the rate of penetration and the number of bound spermatozoa per oocyte. 


\section{RESULTS}

Effect of fucoidan, ZPG's and SBTI on the number of sperm bound to the surface of zona-intact hamster oocytes

In the normal hamster, the in vitro fertilization success rate ranged from $65-80 \%$, with a high number of bound spermatozoa (Fig $1 \mathrm{~A}$ ). We hypothesized that if the PSBD of proacrosin/acrosin participates in this process, we may release those acrosome-reacted sperm bound to the zona by adding fucoidan or solubilized ZPG's. In fact, fucoidan (Fig 1B) and solubilized ZPG's (Fig 1C) did competitively release almost all spermatozoa in the process of penetration. It is noteworthy that the surface of the zona pellucida was marked with many sperm tracks, a specific signature left by sperms in the process of zona pellucida penetration (Fig. 1B insert). In addition, the zona pellucida surface was covered with many acrosomal ghosts left by sperm that underwent the acrosome reaction (Fig. 1C and 1B, arrowheads). On the contrary, SBTI did not detach spermatozoa once they were already bound to the zona pellucida (Fig 1D).

Pre-incubation of zona-intact hamster oocytes with boar acrosin or trypsin

Our next goal was to determine if enzymatic modification of zona-intact hamster oocytes modify the binding and/ or fertilization rate. To this end, we incubate zona-intact
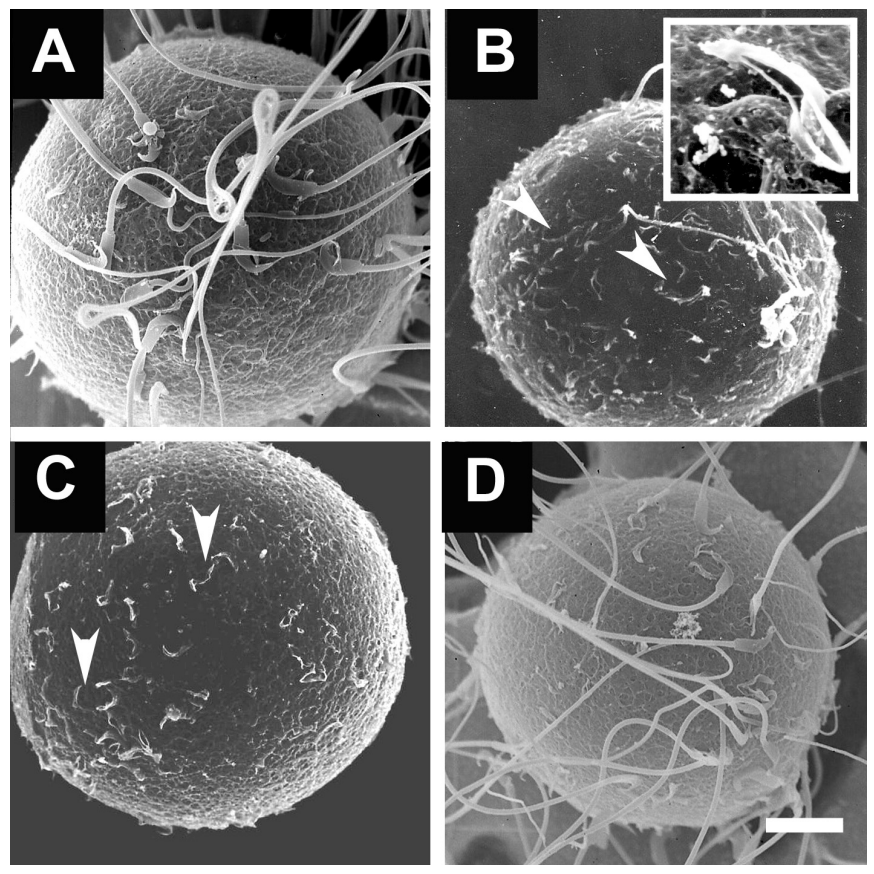

Figure 1: Scanning electron microscopy of hamster in vitro fertilization. (A) Control showing capacitated hamster sperm on the surface of the zona pellucida. When either fucoidan (B) or solubilized ZPG's (C) were added to the medium, the number of sperm decreased significantly relative to controls. These eggs showed many holes or sperm tracks, left by sperm in the process of zona penetration (arrowheads). The insert shows a sperm track besides an acrosomal ghost. (D) SBTI did not affect the number of sperm bound to the zona. hamster oocytes for 5 or 10 min with 1.5 or $3 \mathrm{U}$ of acrosin, or for $5 \mathrm{~min}$ with $1.5 \mathrm{U}$ of trypsin (see Materials and Methods). Neither trypsin or acrosin treatment had any effect on surface appearance of the zona pellucida, as evaluated under the scanning electron microscope (Fig 2A). Treated eggs displayed a zona pellucida with fenestrations typical of those observed in controls (Fig 2A, insert). Fertilization of oocytes treated for 5 min with $1.5 \mathrm{U}$ of acrosin was similar to controls (Fig 2A, 3A, B). However, eggs treated for 10 min with 1.5 or $3 \mathrm{U}$ of acrosin showed a significantly lower fertilization rate and number of bound spermatozoa as compared with controls (Fig 3A, $\mathrm{B}, \mathrm{p}<0.05)$. Interestingly, the percentage of fertilized oocytes
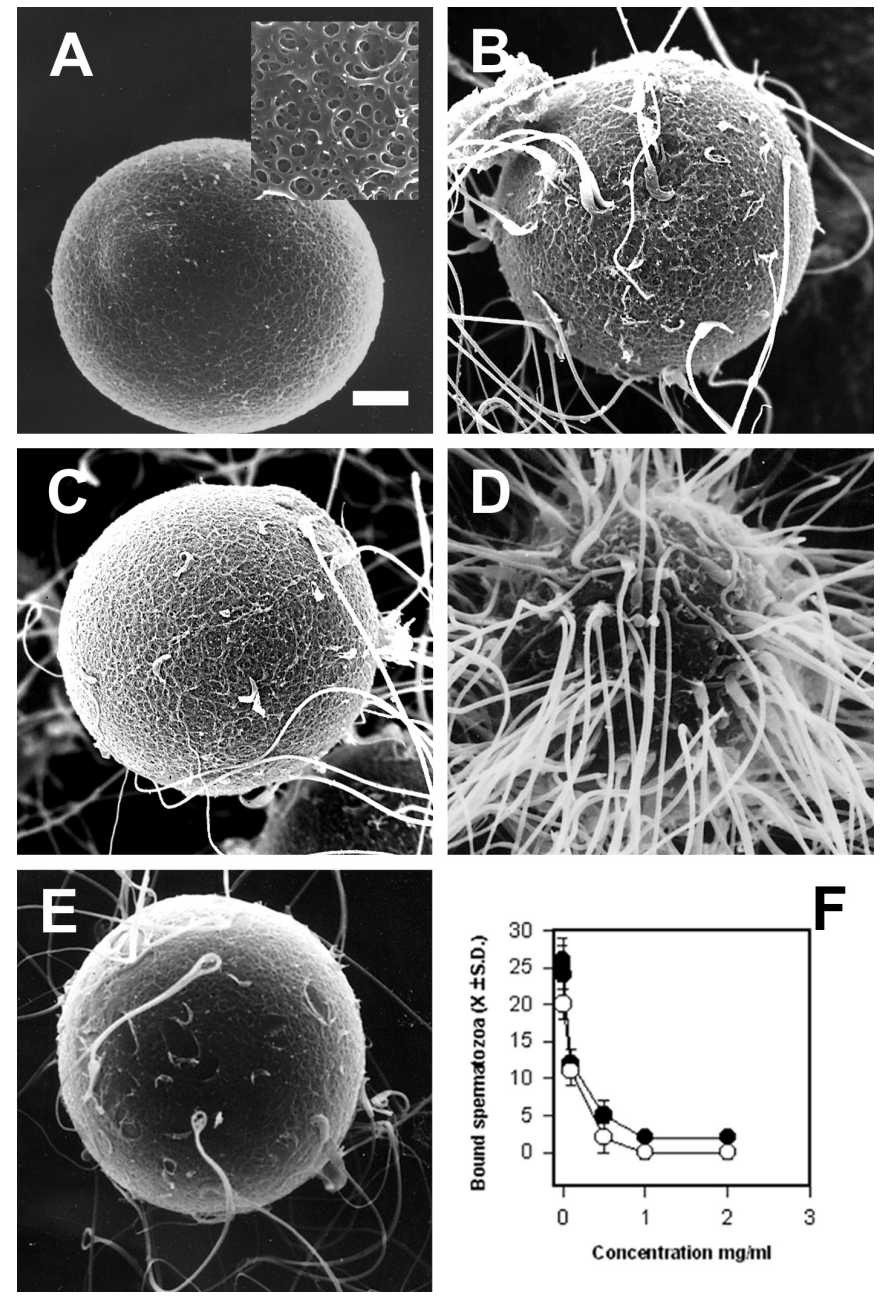

Figure 2: In vitro fertilization of acrosin-treated hamster oocytes. (A) Freshly ovulated hamster oocytes were incubated with $3 \mathrm{U}$ of acrosin for $10 \mathrm{~min}$ and then processed by scanning electron microscopy. The insert shows a magnification of the zona pellucida surface. Hamster oocytes treated with (B) $1.5 \mathrm{U}$ of acrosin for $5 \mathrm{~min}$ and (C) $1.5 \mathrm{U}$ of trypsin for $10 \mathrm{~min}$ were incubated with capacitated spermatozoa as described in Materials and Methods. (D) Hamster oocyte treated with $3 \mathrm{U}$ of acrosin for $10 \mathrm{~min}$ and then incubated with capacitated hamster sperm. Observe the increased number of bound sperm compared to $B$ and $C$. (E) Fertilized hamster oocytes treated with $1.5 \mathrm{U}$ of acrosin for $5 \mathrm{~min}$ and then incubated with $1 \mathrm{mg} / \mathrm{ml}$ of ZPG's. (F) Displacement of bound hamster spermatozoa to acrosin-treated oocytes by fucoidan (black circles) or ZPG's (white circles). 
incubated for $10 \mathrm{~min}$ with $3 \mathrm{U}$ of acrosin was significantly lower than controls (Fig. $3 \mathrm{~A}{ }^{*} \mathrm{p}<0.05$ ). On the contrary, the number of bound spermatozoa was significantly higher than controls (Fig 2D, 3B * $\mathrm{p}<0.05$ ). Trypsin-treated oocytes showed a significant reduction in the number of bound sperm and fertilization rate compared to controls (Fig 2C and 3A; B; $p<0.05$ ). The effect of acrosin on the zona pellucida was due to its enzymatic activity, since pre-treatment of the extract with SBTI or fucoidan abrogates its effect upon sperm binding and fertilization (Fig 3B, insert). It is worth noting that acrosin at levels lower than $1.5 \mathrm{U}$ had no effect on the fertilization rate compared to controls. On the other hand, acrosin at concentrations higher than $3 \mathrm{U}$ had a detrimental effect on zona pellucid structure (data not shown).

To confirm that the binding sites of spermatozoa were not different from controls in eggs treated with acrosin and trypsin, we performed a competitive-displacement assay with fucoidan

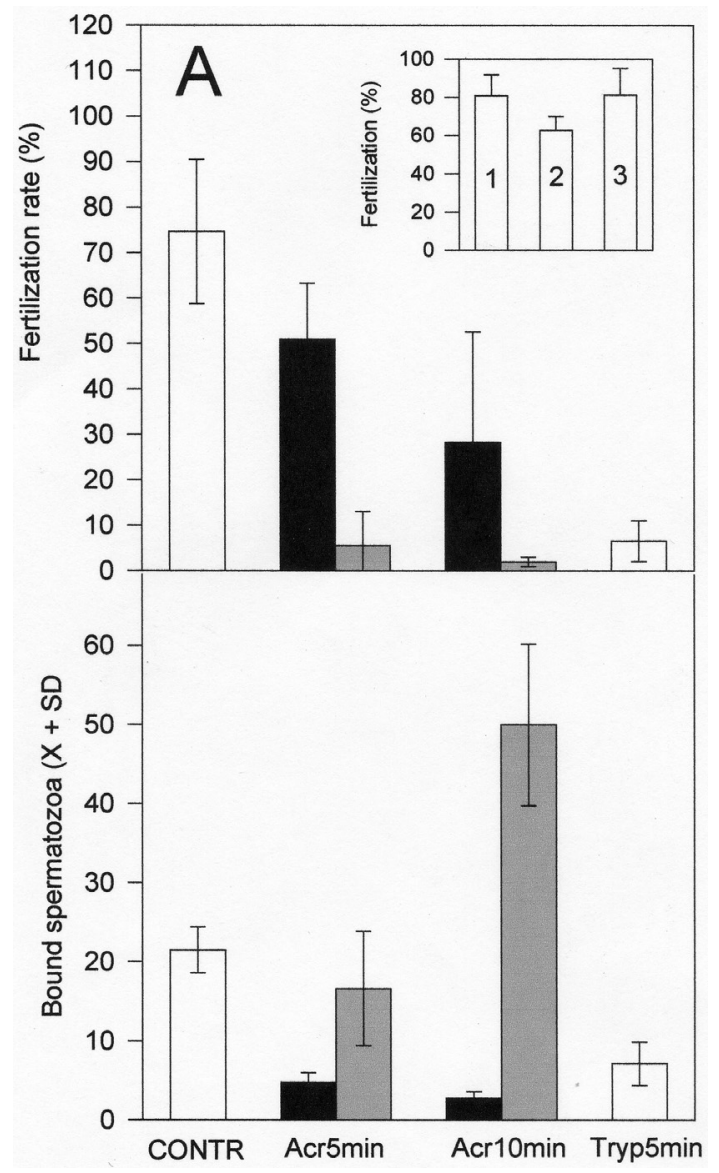

Figure 3: In vitro fertilization of acrosin-treated hamster oocytes: (A) Fertilization rate of controls (CONTR) and oocytes treated with $1.5 \mathrm{U}$ (black bars) or $3 \mathrm{U}$ (gray bars) of acrosin treated for 5 (Acr5min) or $10 \mathrm{~min}$ (Acr10min). The insert shows the fertilization rate of hamster oocytes incubated for $10 \mathrm{~min}$ with 1.5 (1) or $3 \mathrm{U}(2)$ of acrosin or trypsin (3) in the presence of SBTI. (B) Number of sperm bound ( \pm S.D.) to the zona pellucida of controls (CONTR) and oocytes treated with $1.5 \mathrm{U}$ (black bars) or $3 \mathrm{U}$ (gray bars) of acrosin for 5 (Acr5min) or $10 \mathrm{~min}$ (Acr10min). ${ }^{*} \mathrm{p}<0.05,{ }^{* *} \mathrm{p}<0.01$ and solubilized ZPG's. The number of bound spermatozoa was significantly reduced when acrosin-treated oocytes (1.5 U for 5 min) were incubated with fucoidan or solubilized ZPG's (Fig 2E, 2F). Fucoidan and solubilized ZPG's also competitively displaced bound spermatozoa from trypsin-treated oocytes (data not shown).

\section{DISCUSSION}

Since the seminal observations that purified ZP2 does not inhibit the binding of acrosome-intact sperm to mouse eggs in vitro, and it only binds to acrosome-reacted sperm, this glycoprotein was strongly implied as the secondary receptor for sperm (Bleil et al., 1981; Bleil et al., 1988). It is not clear yet which sugars are involved in this interaction, but in vitro studies have suggested that it is stereo specific, with the participation of polysulphated sugar residues (Jones, 1991; Lo Leggio et al., 1994). One is a terminal $\beta-1,3$ galactose (Bleil and Wassarman, 1988) and the other is a terminal $\mathrm{N}$-acetylglucosamine proposed to bind $\beta-1,4$ galactosyl transferase, a putative sperm receptor (Miller and Ax, 1990; Miller et al., 2002). Furthermore, the continued fertility of mutant mice lacking either the enzyme that adds terminal $\beta-1,3$ galactose (Thall et al., 1995)or b-1,4 galactosyltransferase (Shi et al., 2001) makes it unlikely that these are the sole determinants of mouse sperm binding. Therefore, the mechanism of interaction between zona pellucida and the sperm remains unsolved.

Here we have shown that the number of sperm binding sites in the zona pellucida changes with protease treatment, without changing the macroscopic structure of the zona. However, the fertilization rate decreased under this condition. Recently it has been proposed that a specific supramolecular structure of mammalian zona pellucida is important to achieve fertilization and polyspermy block in mammals (Gahlay et al., 2010; Rankin et al., 2003). This model comes from results where mouse ZP1 and ZP3 has been replaced by their human homologus in transgenic mice. Nonetheless, the human proteins were able to form a stable and well-organized zona pellucida at the macroscopic level; the zona is not functionally active, as with the mouse proteins (Gahlay et al., 2010; Rankin et al., 2003). Thus, the simplest explanation for our results is that acrosin treatment disrupts and/or disorganizes the supramolecular structure of hamster zona pellucida, (mainly the carbohydrates moieties), making the binding sites for spermatozoa unavailable. Interestingly, the highest number of bound spermatozoa was observed with the highest amount of acrosin at the longest incubation times. It is possible that this condition may be similar to the sperm passage through the zona pellucida, where probably a high acrosin concentration is released locally in order to unmask new secondary binding sites in a stereo-specific orientation, allowing the activation of a new set of acrosomal proteases and the further advance of the sperm. This hypothesis puts acrosomal protease activity as a key element in order to expose secondary binding sites. The fact that after treatment with acrosin we observed an increased number of sperm bound to the zona, but a decrease in the fertilization rate, suggest that the newly unmasked binding sites are not in the proper orientation to allow completed sperm penetration. Why does the exposure of new binding sites decrease the fertilization rate? One possible explanation is that an increase in the number of bound 
spermatozoa to the zona will lead to an inefficient association among them. Earlier ultrastructural studies have suggested that in order to penetrate the oocyte, the spermatozoon must associate in a oblique fashion through the dorsal/ventral and anterior margin. In fact, in vitro fertilization with high sperm concentrations $(48,000$ sperms $/ \mathrm{ml})$ leads to both a decrease in the number of bound sperm to the zona and a lower fertilization rate (Jedlicki et al., 1988). Ultrastructural studies have shown that at this concentration, spermatozoa were associated in a perpendicular and not oblique fashion. An alternative explanation is that protease-treatment exposes new binding sites on the zona pellucida and increases the interaction with the sperm. In this model, the spermatozoa will be trapped in the zona due to the increase in the number of binding sites in the zona. This idea reinforces a previous model in which the interaction of acrosome-reacted spermatozoa should be strong enough to support its binding to the zona, but it should weaken in order to allow the movement of the sperm through the zona. In this model, the proacrosin/ acrosin was envisioned as the main zona-binding protein in the acrosome. Proacrosin binding to the zona induces its activation into acrosin, which no longer interacts with the zona and it is released to the extracellular milieu (Barros et al., 1992; Moreno et al., 1999; Topfer-Petersen and Cechova, 1990). Then, the sperm moves and a new round of attachment/detachment starts all over again.

For a long time acrosomal protease acrosin had been regarded as the main zona binding protein (Barros et al., 1996). The mechanism of interaction involves recognition of polysulphate groups on ZP glycoproteins by basic residues on the surface of proacrosin/acrosin, in a manner similar to that for heparin-anti-thrombin III (Moreno and Barros, 2000). Binding of sulphate groups requires the correct presentation of positively charged basic residues of the surface of the proacrosin/acrosin. We have shown previously that model polysulfates such as fucoidan prevent activation of proacrosin into acrosin, a process that was mediated by a 18-residues peptide containin) a cluster of three basic amino acids (residues 59-76) (Moreno and Barros, 2000; Moreno et al., 2002). In this study we showed for the first time that fucoidan and solubilized zona pellucida glycoproteins detach bound sperm from the zona pellucida, suggesting that the PSBD is indeed involved in the binding of acrosome-reacted spermatozoa to the zona. Interestingly, SBTI, an inhibitor of the catalytic activity of acrosin did not detach spermatozoa from the zona pellucida, suggesting that the active site of acrosin is not involved in this process during fertilization. Since, enzyme activity is necessary in order to allow the sperm passage through the zona pellucid, our data support the hypothesis that acrosin has at least two functional sites: the active site involved in zona pellucida proteolysis, and the PSBD, involved in the binding to the sulphated glycoprotein of the zona pellucida. In addition, our results suggest that the PSBD binds to a three dimensional structure of polysaccharides in the zona pellucida, putting forward the ZP2 cleavage model of spermzona interaction.

\section{ACKNOWLEDGMENTS}

This manuscript is dedicated to our mentor and friend Prof Claudio Barros. His advice still guides us through the path of science.

\section{REFERENCES}

BARROS C, CAPOTE C, PÉREZ C, CROSBY JA, BECKER MI, DE IOANNES A (1992) Immunodetection of acrosin during the acrosome reaction of hamster, guinea-pig and human spermatozoa. Biol Res 25: 31-40.

BARROS C, CROSBY JA, MORENO RD (1996) Early steps of spermegg interactions during mammalian fertilization. Cell Biol Int 20: 33-39.

BLEIL JD, BEALL CF, WASSARMAN PM (1981) Mammalian sperm-egg interaction: fertilization of mouse eggs triggers modification of the major zona pellucida glycoprotein, ZP2. Dev Biol 86: 189-197.

BLEIL JD, GREVE JM, WASSARMAN PM (1988) Identification of a secondary sperm receptor in the mouse egg zona pellucida: role in maintenance of binding of acrosome-reacted sperm to eggs. Dev Biol 128: 376-385.

CODELIA VA, CORTÉS CJ, MORENO RD (2005) Inhibition of the vacuolar $\mathrm{H}(+)$-pump with bafilomycin $\mathrm{A} 1$ does not induce acrosome reaction or activate proacrosin in mouse spermatozoa. Biochem Biophys Res Commun 337: 1337-1344.

CORTÉS CI, CODELIA VA, MANOSALVA I, DE LANGE J, DE LOS REYES M, MORENO RD (2006) Proacrosin/acrosin quantification as an indicator of acrosomal integrity in fresh and frozen dog spermatozoa. Anim Reprod Sci 93: 165-175.

CROSBY JA, JONES R, BARROS C, CARVALLO P (1998) Characterization of the functional domains of boar acrosin involved in nonenzymatic binding to homologous zona pellucida glycoproteins. Mol Reprod Dev 49: 426-434.

FLORMAN HM, WASSARMAN PM (1985) O-linked oligosaccharides of mouse egg ZP3 account for its sperm receptor activity. Cell 41: 313-324.

GAHLAY G, GAUTHIER L, BAIBAKOV B, EPIFANO O, DEAN J (2010) Gamete recognition in mice depends on the cleavage status of an egg's zona pellucida protein. Science 329: 216-219.

HOWES E, PASCALL JC, ENGEL W, JONES R (2001) Interactions between mouse ZP2 glycoprotein and proacrosin; a mechanism for secondary binding of sperm to the zona pellucida during fertilization. J Cell Sci 114: 4127-4136.

HOWES L, JONES R (2002) Interactions between zona pellucida glycoproteins and sperm proacrosin/acrosin during fertilization. J Reprod Immunol 53: 181-192.

JANSEN S, JONES R, JENNECKENS I, MARSCHALL B, KRIEGESMANN B, COADWELL J, BRENIG B (1998) Site-directed mutagenesis of boar proacrosin reveals residues involved in binding of zona pellucida glycoproteins. Mol Reprod Dev 51: 184-192.

JEDLICKI A, SALGADO AM, BARROS C (1988) Relationship between sperm concentration and the rate of fertilization in vitro of golden hamster eggs. Microsc Electron Biol Celular 12: 185-195.

JONES R (1989) Identification of carbohydrate-binding proteins in mammalian spermatozoa (human, bull, boar, ram, stallion and hamster) using [125I]fucoidin and [125I]neoglycoprotein probes. Hum Reprod 4: 550-557.

JONES R (1991) Interaction of zona pellucida glycoproteins, sulphated carbohydrates and synthetic polymers with proacrosin, the putative egg-binding protein from mammalian spermatozoa. Development 111: 1155-1163.

LO LEGGIO L, WILLIAMS RM, JONES R (1994) Some effects of zona pellucida glycoproteins and sulfated polymers on the autoactivation of boar sperm proacrosin and activity of beta- acrosin. J Reprod Fertil 100: 177-185.

MILLER DJ, AX RL (1990) Carbohydrates and fertilization in animals. Mol Reprod Dev 26: 184-198.

MILLER DJ, SHI X, BURKIN H (2002) Molecular basis of mammalian gamete binding. Recent Prog Horm Res 57: 37-73.

MORENO R, ORIHUELA P, BARROS C (2001) Differential effects of polysulphates between mouse and hamster during in vitro fertilization. Andrologia 33: 19-25.

MORENO RD, ALVARADO CP (2006) The mammalian acrosome as a secretory lysosome: new and old evidence. Mol Reprod Dev 73: 14301434.

MORENO RD, BARROS C (2000) A basic 18-amino acid peptide contains the polysulfate-binding domain responsible for activation of the boar proacrosin/ acrosin system. Biol Reprod 62: 1536-1542.

MORENO RD, BUSTAMANTE E, SCHATTEN G, BARROS C (2002) Inhibition of mouse in vitro fertilization by an antibody against a unique 18-amino acid domain in the polysulfate-binding domain of proacrosin/ acrosin. Fertil Steril 77: 812-817. 
MORENO RD, HOSHI M, BARROS C (1999) Functional interactions between sulphated polysaccharides and proacrosin: implications in sperm binding and digestion of zona pellucida. Zygote 7: 105-111.

MORENO RD, SEPÚLVEDA MS, DE IOANNES A, BARROS C (1998) The polysulphate binding domain of human proacrosin/acrosin is involved in both the enzyme activation and spermatozoa-zona pellucida interaction. Zygote 6: 75-83.

RANKIN TL, COLEMAN JS, EPIFANO O, HOODBHOY T, TURNER SG, CASTLE PE, LEE E, GORE-LANGTON R, DEAN J (2003) Fertility and taxon-specific sperm binding persist after replacement of mouse sperm receptors with human homologs. Dev Cell 5: 33-43.

RICHARDSON RT, O'RAND MG (1996) Site-directed mutagenesis of rabbit proacrosin. Identification of residues involved in zona pellucida binding. J Biol Chem 271: 24069-24074.
SHI X, AMINDARI S, PARUCHURU K, SKALLA D, BURKIN H, SHUR BD, MILLER DJ (2001) Cell surface beta-1,4-galactosyltransferase-I activates $G$ protein-dependent exocytotic signaling. Development 128: 645-654.

SOKAL RR (1995) Biometry: the principles and practice of statistic in biological research In: R. R. Sokal, J. Rohlf, (Ed.). New York

W. H. Freeman, pp. 887.

THALL AD, MALY P, LOWE JB (1995) Oocyte Gal alpha 1,3Gal epitopes implicated in sperm adhesion to the zona pellucida glycoprotein ZP3 are not required for fertilization in the mouse. J Biol Chem 270: 21437-21440.

TOPFER-PETERSEN E, CECHOVA D (1990) Zona pellucida induces conversion of proacrosin to acrosin. Int J Androl 13: 190-196.

WASSARMAN PM (2008) Zona pellucida glycoproteins. J Biol Chem 283: 24285-24289.

WASSARMAN PM, JOVINE L, LITSCHER ES (2001) A profile of fertilization in mammals. Nat Cell Biol 3: E59-64. 